\title{
Eşdeğer Deprem Yükü Yöntemi Kullanılarak Tarihi Bir Yığma Yapının Sismik Performans Düzeyinin Belirlenmesi
}

\author{
Atila KUMBASAROGLU*D, Alper ÇELIK ${ }^{\mathbb{D}}$
}

Erzincan Binali Yıldırım Üniversitesi Mühendislik Fakültesi, İnşaat Mühendisliği Bölümü, Erzincan, Türkiye

Geliş / Received: 13/09/2019, Kabul / Accepted: 15/12/2019

\begin{abstract}
$\ddot{O} \mathbf{z}$
Tarih boyunca Anadolu toprakları, birçok medeniyete ev sahipliği yapmıştır. Bu sebeple ülkemizde tarihi yapılar azımsanmayacak sayıdadır. Bununla birlikte ülkemizin, aktif deprem kuşağı içerisinde yer alması sebebiyle birçok tarihi yapı, meydana gelen depremlerden zarar görmüş veya yıkılmıştır. Kültür mirası açısından önem arz eden tarihi yapılarımızın, gelecek kuşaklara güvenle aktarılabilmesi için sismik performans seviyelerinin doğru ve hızlı bir şekilde belirlenerek gerekli müdahalelerin yapılması oldukça önemlidir. Çalışma kapsamında örnek olarak ele alınan Tarihi Yanıkoğlu Camisinde yapılan ölçümler ve gözlemlere dayalı olarak yapının analitik modeli oluşturulmuştur. Yapı konumuna özel olarak seçilen deprem spektrumları ile eşdeğer deprem yükü hesaplanmıştır. Yapının kendi ağırlığı ve hesaplanan deprem kuvvetleri altında yapılan analizlerden elde edilen sonuçlara bağlı olarak yapının sismik performans düzeyi 2017 yılında Vakıflar Genel Müdürlüğünce yayımlanan Tarihi Yapılar İçin Deprem Risklerinin Yönetimi Kılavuzuna göre belirlenmiştir. Bu çalışma ile tarihi yığma yapıların sismik performanslarının değerlendirilmesinde eşdeğer deprem yükü yöntemi kullanılarak pratik bir yaklaşım ortaya konulmuştur.
\end{abstract}

Anahtar Kelimeler: Tarihi yapı, Eşdeğer deprem yükü, deprem spektrumu, sismik performans seviyesi.

\section{Assessment of Seismic Performance Level of a Historical Masonry Structure Using Equivalent Seismic Load Method}

\begin{abstract}
Throughout history, Anatolian lands have been home to many civilizations. For this reason, the historical structures in our country are considerable. However, due to the fact that our country is located within the active earthquake zone, many historical buildings have been damaged or destroyed by the earthquakes. In order to transfer the historical structures which are important in terms of cultural heritage to the next generations with confidence, it is very important to determine the seismic performance levels accurately and quickly and to make the necessary interventions. The analytical model of the building was established based on the measurements and observations made at the Historical Yanıkoglu Mosque, which was taken as an example within the scope of the study. Equivalent earthquake load was calculated with earthquake spectra specially selected for the structure location. The seismic performance level of the building was determined according to the Seismic Risk Management Guide for Historic Buildings published by the General Directorate of Foundations in 2017, depending on the results of the analyzes made under the earthquake's own weight and calculated earthquake forces. In this study, a seismic performance of historical masonry structures is evaluated by using the equivalent earthquake load method.
\end{abstract}

Keywords: Historical structures, equivalent earthquake load, earthquake spectrum, seismic performance level. 


\section{Giriş}

Türkiye, Avrupa'da bulunan önemli derecede deprem tehlikesi içeren ülkelerden biri olup, çok sayıda önemli depreme maruz kalmıştır. $\mathrm{Bu}$ depremlerde tarihi yapılar önemli derecede hasar görmüş veya toptan yıkılmıştır. Buna rağmen, yurdumuzda tarihi yapıların deprem tehlikesini belirlemede ve gerektiğinde güçlendirmede kullanılacak bir teknik belge bulunmadığından, Vakıflar Genel Müdürlüğü tarafından, Venedik Tüzüğü ve ICOMOS İlkeleri 1şı̆̆ında bir teknik belge hazırlanmıştır. Bu belgede tarihi yapılarda bilgi toplanması, yapıdaki malzeme kalitesinin belirlenmesi için kullanılacak deneyler, yapıdaki hasarların yorumlanması, yapının taşıyıcı sisteminin modellenmesi, analizi ve güçlendirme önerilerine ait bilgiler bulunmaktadır. 2017 yilında tamamlanan bu belge ayrica tarihi yapılara depremden sonra acil ve kısa vadeli müdahalelere ait bilgiler de içermektedir. Günümüzde restorasyonu ve güçlendirilmesi önem arz eden tarihi yapıların, bilgisayar programları yardımıyla statik olarak modellenmesi, analiz edilmesi, depremsellik açısından incelenmesi ve özgünlüğünü bozmadan güçlendirilmesi oldukça önemlidir.

$\mathrm{Bu}$ kapsamda literatürdeki çalışmalar oldukça sınırlıdır. Çalışmalarda genellikle bu tip yapıların mimari olarak incelenmesini kapsamaktadır. Şekil 1'de gösterildiği üzere, örnek olarak seçilen tarihi Yanıkoğlu Camisinin sonlu elemanlar modeli oluşturulmuş ve eşdeğer deprem yükü yönteminde göre hesaplanan deprem kuvvetleri yapıya etki ettirilip, doğrusal performans analizi yapılmıştır.

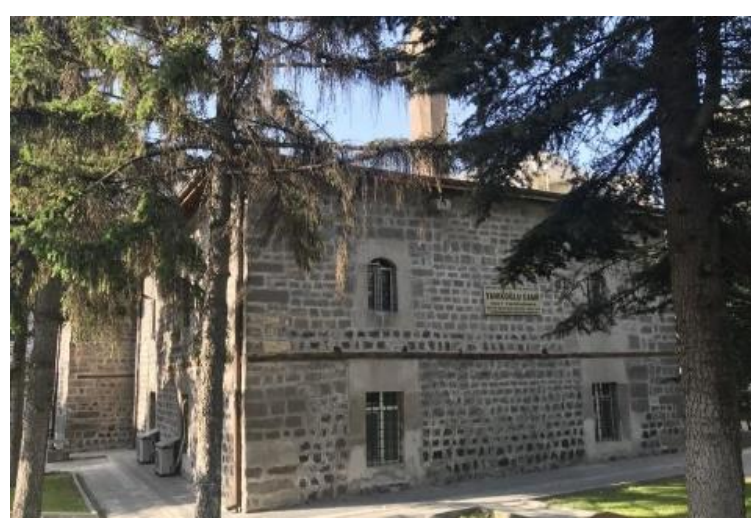

Şekil 1. Tarihi Yanıkoğlu Cami

\subsection{Yapının genel özellikleri}

Kayseri'nin Melikgazi ilçesi Yanıkoğlu Mahallesinde bulunan Yanıkoğlu Camisi 1657 yılında inşa edilmiştir. Yapı klasik Osmanlı mimarisi özelliğini taşımaktadır. Cami taşıyıcı sistemi yığma duvarlar ile birleştirilmiş ahşap taşıyıcı sütun ve kirişlerden oluşmaktadır. Yapı taş duvar sistemi 1,1 m kalınlığındadır. Yapının iç kısmı 10.55 x $12.29 \mathrm{~m}$ plan boyutlarına sahiptir. Caminin tavan döşemesi içeri kısımda dört, dışında dört olmak üzere 5,3 m yüksekliğinde toplam sekiz adet ahşap sütun üzerinde inşa edilmiştir. Yapının 3 boyutlu mimari modeli Şekil 2 de görülmektedir.

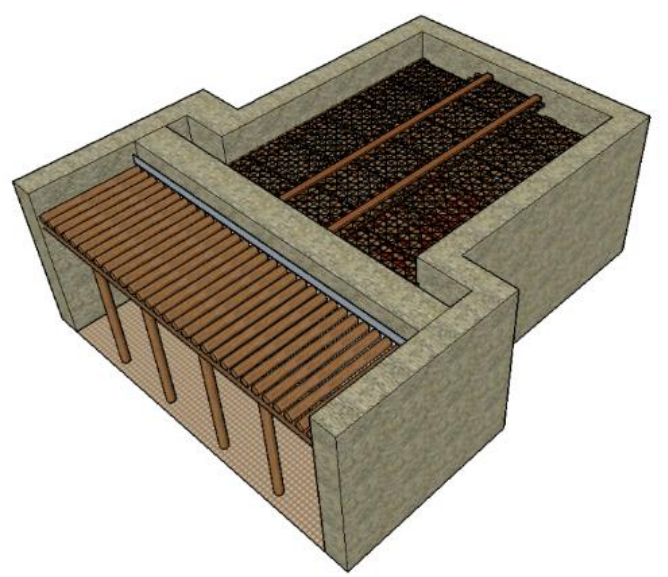

Şekil 2. Mimari Model 


\subsection{Bölgenin depremselliği}

Vakıflar Genel Müdürlüğünce hazırlanan Tarihi Yapıların Deprem Risklerinin Yönetimi Kılavuzunda belirtildiği üzere, tarihi yapılardaki deprem etkisinin belirlenmesi ile ilgili veriler Türkiye Bina Deprem Yönetmeliği'nde (TBDY-2018) tanımlanmış olup, bununla ilgili olarak AFAD tarafından oluşturulan, Türkiye Deprem Tehlikesi Haritaları verilmiştir. Yerel öneme sahip olan tarihi yapıların taşıyıc1 sistem güvenliğin belirlenmesi için Deprem Yer Hareketi Düzeyi-3 (50\%50-72 Y1l) önerilmiştir. Bu verilerle birlikte Şekil 3'de gösterildiği gibi, AFAD'ın interaktif deprem tehlikesi haritaları kullanılarak, yapının bulunduğu konumuna özel deprem spektrumları tanımlanmıştır.

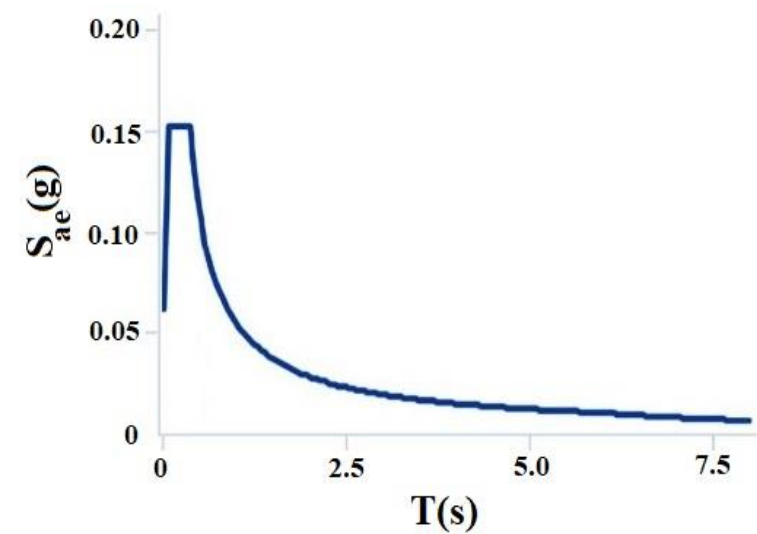

Şekil 3. Yapıya Ait Spektrum-Zaman Grafiği

\subsection{Eșdeğer deprem yükü hesabı}

Yapının toplam eşdeğer deprem yükünün belirlenmesi için, Türkiye Bina Deprem
Yönetmeliğinin (2019) Dördüncü bölümünde verilen Denklem 1 eşitliği kullanılmıştır.

$\mathrm{V}_{\mathrm{t}} \mathrm{E}^{(\times)}=\mathrm{m}_{\mathrm{t}} \times \mathrm{S}_{\mathrm{aR}}\left(\mathrm{T}_{\mathrm{p}}^{(\times)}\right) \geq 0.04 \times \mathrm{m}_{\mathrm{t}} \times \mathrm{I} \times \mathrm{S}_{\mathrm{DS}} \times \mathrm{g}$

Denklem 1'deki ifadelerden, $\mathrm{V}_{\mathrm{t}} \mathrm{E}^{(\times)}$, hesap yapılan deprem doğrultusunda binanın tümüne etkiyen toplam eşdeğer deprem yükünü, $m_{t}$, binanın toplam kütlesini, $\mathrm{S}_{\mathrm{aR}}\left(\mathrm{T}_{\mathrm{p}}^{(\mathrm{x})}\right)$, hesap yapilan deprem doğrultusunda azaltılmış tasarım spektral ivmesini, $\left(\mathrm{T}_{\mathrm{p}}^{(\mathrm{x})}\right)$, hesap yapılan deprem doğrultusunda binanın hâkim doğal titreşim periyodunu, I, bina önem katsayısını, $S_{D S}$, kısa periyot tasarım spektral ivme katsayısını ve $\mathrm{g}$, yerçekimi ivmesini tanımlamaktadır.

Türkiye Bina Deprem Yönetmeliğinde süneklik düzeyi sınırlı yığma yapı sistemi için taşıyıcı sistem davranış katsayısının 2.5 olarak alınması önerilmiştir. Oluşturulan sonlu elemanlar modelinde yapının ahşap taşıyıcı sistem dâhil toplam ağırlığ $\mathrm{m}_{\mathrm{t}}=$ $8182.28 \mathrm{kN}$ olarak elde edilmiştir. Kısa periyot harita spektral ivme katsayısı $S_{S}$ ve 1.0 saniye periyot için harita spektral ivme katsay1s1 $\mathrm{S}_{1}$, tdth.afad.gov.tr interaktif web sayfasından yapı konumuna bağlı olarak $\mathrm{S}_{\mathrm{S}}=0.118$ ve $\mathrm{S}_{1}=0.037$ olarak elde edilmiştir. Elde edilen bütün değerler Tablo 1 'de özetlenmiştir. Her iki doğrultuda yapıya etkiyecek eşdeğer deprem yükü $491.2 \mathrm{kN}$ olarak hesaplanmıştır.

Tablo 1. Eşdeğer deprem yükü hesab1

\begin{tabular}{ccccccccccccc}
\hline & $\mathrm{T}_{\mathrm{p}}^{(\times, y)}$ & $\mathrm{R}$ & $\mathrm{m}_{\mathrm{t}}$ & $\mathrm{S}_{\mathrm{S}}$ & $\mathrm{S}_{1}$ & $\mathrm{~S}_{\mathrm{DS}}$ & $\mathrm{S}_{\mathrm{D} 1}$ & $\mathrm{~T}_{\mathrm{A}}$ & $\mathrm{T}_{\mathrm{B}}$ & $\mathrm{T}_{\mathrm{L}}$ & $\mathrm{S}_{\mathrm{aR}}(\mathrm{T})$ & $\mathrm{V}_{\mathrm{t}} \mathrm{E}^{(\times, y)}$ \\
Birim & $\mathrm{s}$ & - & $\mathrm{kN}$ & - & - & - & - & $\mathrm{s}$ & $\mathrm{s}$ & $\mathrm{s}$ & $\mathrm{m} / \mathrm{s}^{2}$ & $\mathrm{kN}$ \\
Büyüklük & 0.51 & 2.5 & 8182.3 & 0.118 & 0.037 & 0.153 & 0.056 & 0.072 & 0.362 & 6.000 & 0.098 & 491.2 \\
\hline
\end{tabular}




\section{Materyal ve Metot}

\subsection{Modelin olușturulması}

Tarihi Yanıkoğlu Camisinin yığma taşıyıcı sistemine ait sonlu elemanlar modeli yap1 boyutlarına uygun bir şekilde SAP 2000 (v.15) programında oluşturulmuştur. Modelde, yığma duvarlar için moloz taş ve duvar üstündeki hatıllar için ahşap olmak üzere iki tip malzeme bulunmaktadır. Modelde bulunan malzemelerin mekanik özelliklerini için mevcut literatürden faydalanılmıştır. Yı̆̆ma taş duvar malzemesinin mekanik özellikleri için, Magenes and Penna (2011) tarafindan Tablo 2'de önerilen büyüklükler kullanılmıştır. Ahşap malzemesi için, Efe ve Çağatay (2011) tarafından yapılan çalışmasından yararlanılmıştır. Ayrıca, Green et. al. (1999) tarafindan yapilan çalışmada ceviz ağacı Poisson oranının yaklaşık 0.495 olduğu belirlenmiştir. Ahşap malzemesine ait mekanik özellikler ise Tablo 3'te verilmiştir.

Tablo 2. Yığma duvar mekanik özellikleri

\begin{tabular}{ll}
\hline Basınç Dayanımı $\left(f_{c}\right)$ & $0,6 \mathrm{MPa}$ \\
Kayma Dayanımı $(\tau)$ & $20 \mathrm{KPa}$ \\
Elastisite Modülü $(\mathrm{E})$ & $690 \mathrm{MPa}$ \\
Kayma Modülü $(\mathrm{G})$ & $115 \mathrm{MPa}$ \\
Birim Hacim Ağırlığ $1(\mathrm{w})$ & $19 \mathrm{kN} / \mathrm{m}^{3}$ \\
\hline
\end{tabular}

Tablo 3. Ceviz ağacı mekanik özellikleri

\begin{tabular}{ll}
\hline Basınç Dayanımı $\left(\mathrm{f}_{\mathrm{c}}\right)$ & $5,69 \mathrm{MPa}$ \\
Kesme Dayanımı $(\tau)$ & $18,08 \mathrm{KPa}$ \\
Elastisite Modülü $(\mathrm{E})$ & $9125 \mathrm{MPa}$ \\
Birim Hacim Ağırlığ $(\mathrm{w})$ & $6,10 \mathrm{kN} / \mathrm{m}^{3}$ \\
\hline
\end{tabular}

SAP 2000 (v.15) programında modele ait malzeme özelikleri tanımlandıktan sonra yapısal elemanların boyutlarına uygun olacak şekilde kesitler tanımlanmıştır. Taş duvar ve ahşap hatıllar, üzerlerindeki gerilme dağılımlarının görülebilmesi amaciyla area (alan) tanımlama özelliği kullanılarak modellenmiştir. Taş duvarın kalınlığı alınan rölevesine göre $110 \mathrm{~cm}$ 'dir. Yapının mevcut kesme taş imalatının $+2,6$ $\mathrm{m}$ kotunda ahşap hatıl bulunmaktadır. Yapı sismik performansının daha sağlıklı bir şekilde değerlendirilebilmesi için ahşap hatıl detay1 sonlu elemanlar modelinde dikkate alınmıştır. Alanlar değişen malzeme sınırları dikkate alınarak yeterli sayıda sonlu elemanlar ağına ayrılmıştır. $\mathrm{Bu}$ işlemde yük aktarımının doğru şekilde iletilebilmesi ve gerçeği yansıtabilmesi için sonlu elemanların geometrisine dikkat edilmiştir. Oluşturulan sonlu elemanlar modeli Şekil 4'te gösterilmektedir.



Şekil 4. Yığma duvar sisteminin sonlu elemanlar modeli

\subsection{Ahşap taşıyıcı sistem yüklerinin modele tanımlanması}

Ahşap taşıyıcı sisteme ait masif yüklerin belirlenebilmesi ve bu yüklerin yığma taş duvar modeline doğru bir şekilde tanımlanabilmesi için, sistemin ahşap detayları, yapılan ölçümlere bağlı olarak SAP 2000 (v.15) programında ayrı olarak modellenmiştir. Modelde ahşap sütunlar (kolonlar) üzerinde guseler (eğimli destek), ahşap ana kirişler ve enine dairesel kirişler 
bulunmaktadır. Tamamı ahşap olan taşıyıcı elemanların malzeme mekanik özellikleri için Tablo 3'te verilen büyüklükler kullanılmıştır. İç mekân ahşap taşıyıcı sisteme ait oluşturulan sonlu elemanlar modeli şekil 5'e verilmiştir.

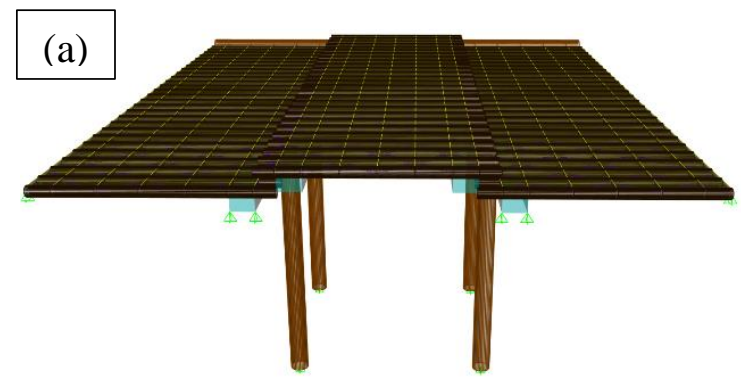

(b)

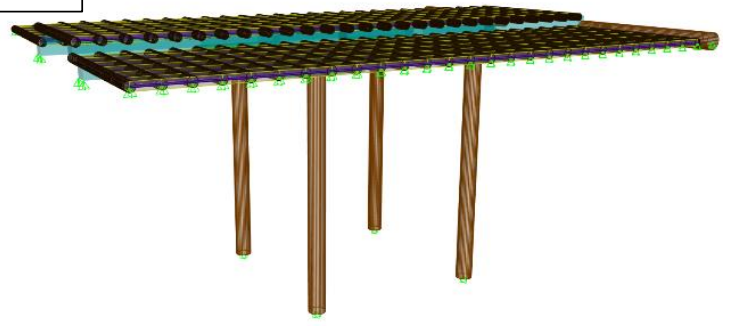

Şekil 5. Ahşap taşı1ıı sistem modeli; (a) perspektif ön görünüş, (b) perspektif yan görünüş

Mevcut yap1 sisteminde çatı döşemesine etki eden $60 \mathrm{~cm}$ kalınlığındaki toprak yükü oluşturulan modele tanımlanmıştır. Bu yük iç mekân döşemesine yayılı olarak 9.5 $\mathrm{kN} / \mathrm{m}^{2}$ olarak etkitilmiştir. Sütun altlarına ankastre (tam bağlı) mesnet tanımlanarak ahşap taşıyıcı sistemin toplam ağırlıkları elde edilmiştir. İç mekân ahşap taşıyıcı sistem ağırlığı 100,31kNf ve dış mekân ahşap taşıyıcı sistem ağırlığı $712.0 \mathrm{kN}$ olarak elde edilmiştir.

Yığma taş duvar sistemine oturan ahşap kiriş uçlarına ayrıca mesnet tanımlanmıştır. Yapılan analiz sonucunda mesnetlerden elde edilen kuvvetler, yığma taş duvar sistemine Şekil 6'da gösterildiği gibi tekil kiriş yükleri ve çizgisel yayılı yükler olarak etkitilmiştir.
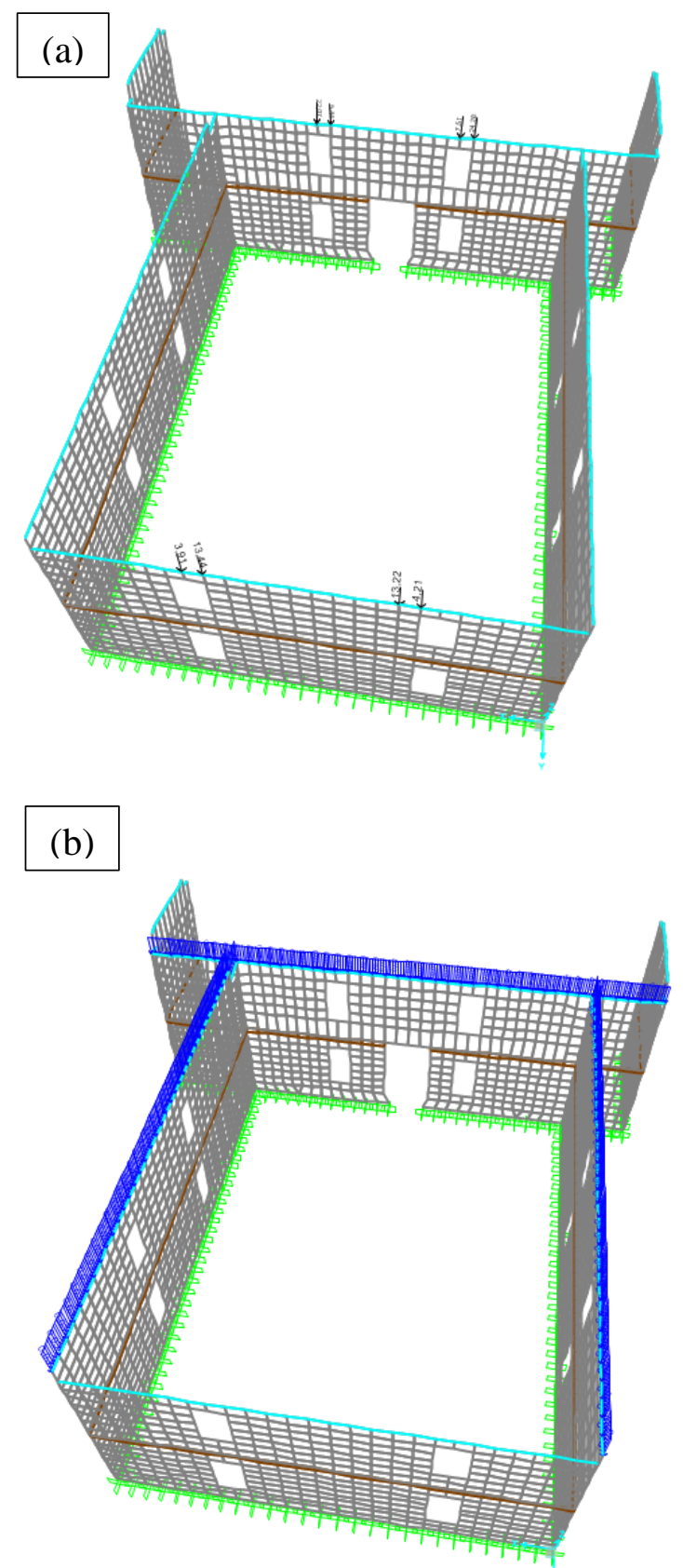

Şekil 6. Ölü yüklerin yığma duvar modeline tanımlanması; (a) tekil kiriş yükleri, (b) çizgisel yayılı yükler

\subsection{Eşdeğer deprem yüklerinin modele tanımlanması}

Türkiye Bina Deprem Yönetmeliği'ne göre planda yatay $X$ ve düşey $Y$ yönlerinde $491.2 \mathrm{kN}$ olarak hesaplanan eşdeğer deprem yükü (Denklem 1), hesap yapılan yön doğrultusundaki duvar alanlarıyla orantılı olacak şekilde paylaştırılmıştır. 
Hesap yapılan yöndeki duvar alanları ile orantılı olarak paylaştırılan deprem yükleri Tablo 4'te özetlenmiştir. Hesaplanan bu yükler duvar uzunluklarına oranlanarak çizgisel yayılı yük olarak döşeme hizasından modele tanımlanmıştır. Duvar isimleri ve hesap yapılan deprem yönleri Şekil 7'de gösterilmektedir.

Tablo 4. Yığma duvarlara etkiyen deprem yükleri

\begin{tabular}{|c|c|c|c|c|c|}
\hline \multicolumn{3}{|c|}{ X Doğrultusu } & \multicolumn{3}{|c|}{ Y Doğrultusu } \\
\hline Duvar & \% Alan & Deprem Yükü & Duvar & \% Alan & Deprem Yükü \\
\hline$A 1$ & 38 & $\begin{array}{c}186.6 \mathrm{kN} \\
13.5 \mathrm{kN} / \mathrm{m}\end{array}$ & $B 1$ & 40 & $\begin{array}{c}196.5 \mathrm{kN} \\
18.5 \mathrm{kN} / \mathrm{m}\end{array}$ \\
\hline$A 2$ & 12 & $\begin{array}{c}58.9 \mathrm{kN} \\
15.7 \mathrm{kN} / \mathrm{m}\end{array}$ & $B 2$ & 8 & $\begin{array}{c}39.3 \mathrm{kN} \\
19.5 \mathrm{kN} / \mathrm{m}\end{array}$ \\
\hline$A 3$ & 38 & $\begin{array}{c}186.6 \mathrm{kN} \\
13.5 \mathrm{kN} / \mathrm{m}\end{array}$ & B3 & 41 & $\begin{array}{c}201.3 \mathrm{kN} \\
18.9 \mathrm{kN} / \mathrm{m}\end{array}$ \\
\hline$A 4$ & 12 & $\begin{array}{c}58.9 \mathrm{kN} \\
15.7 \mathrm{kN} / \mathrm{m}\end{array}$ & B4 & 11 & $\begin{array}{c}54 \mathrm{kN} \\
20.1 \mathrm{kN} / \mathrm{m}\end{array}$ \\
\hline
\end{tabular}

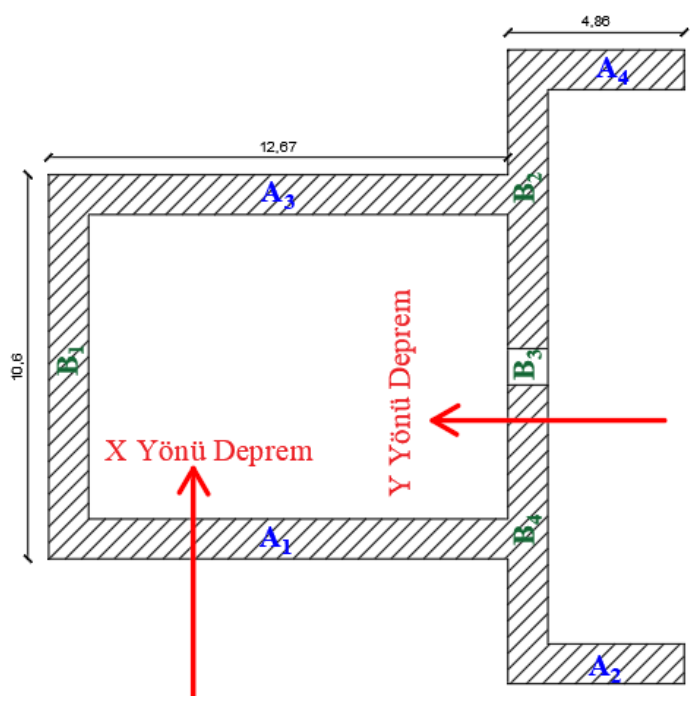

Şekil 7. Hesap yapılan deprem doğrultuları ve duvar isimleri

\section{Bulgular}

Tarihi yapıların önem derecesi, sistem fonksiyonu, kullanıcı ve ziyaretçi sayısına bağlı olarak bu yapılar için kabul edilebilir bir hasar seviyesi tanımlanabilmektedir. Dünya çapında ve çok ziyaretçi alan bir yapıda hedeflenen hasar görebilirlik, en düşük seviyede kalırken, yerel öneme sahip bir tarihi yapıda göreceli olarak daha ileri bir hasar kabul edilebilirdir. Çalışma kapsamında yerel öneme sahip olan tarihi Yanıkoğlu Camisi ele alınmıştır ve yapının sonlu elemanlar modeli oluşturulduktan sonra düşey ve yatay yük etkilerini birlikte değerlendirebilmek için, $\left(G+E_{x}\right)$ ve $\left(G+E_{y}\right)$ olmak üzere iki farklı yük kombinasyonu (birleşimi) tanımlanmıştır. Yük birleşimleri tanımlandıktan sonra modele doğrusal (elastik) analiz uygulanmıştır. Doğrusal analiz sonuçları, taş duvar yanal ötelenme kontrolü, taş duvar kayma güvenliğinin kontrolü ve taş duvar sistemi basınç dayanımı güvenliği olmak üzere üç ayrı başlık altında incelenerek yapının sismik performans düzeyine karar verilmiştir.

\subsection{Taş duvar sistemi yanal ötelenme kontrolü}

Deprem esnasında, elastik sınırlar ötesinde şekil değiştirmelerin olması öngörüldüğü için, şiddetli depremlerde büyük yer değiştirmelerin oluşması kaçınılmaz olmaktadır. Yatay ötelenme rijitliği düşük olan bir yapı, deprem etkisi altında büyük 
yanal ötelenmeler yapmaktadır. Yanal ötelenmenin büyük olması, ikinci mertebe momentlerinin oluşmasına yol açmaktadır. Dolayısıyla, yanal ötelenmelerin büyük olması, yapının deprem davranışını olumsuz etkilemekte ve her bir duvardaki maksimum yanal ötelenme miktarı yapının performans düzeyinin belirlenmesi için gerekli olmaktadır. $\left(\mathrm{G}+\mathrm{E}_{\mathrm{x}}\right)$ ve $\left(\mathrm{G}+\mathrm{E}_{\mathrm{y}}\right)$ yük birleşimlerinin analiz sonuçları ayrı ayrı göz önüne alınarak, taş duvarda oluşan maksimum yatay yer değiştirmenin ilgili duvar yüksekliğine oranı yüzdesel olarak Tablo 5'te özetlenmiştir. Tarihi Yanıkoğlu
Camisi, $110 \mathrm{~cm}$ kalınlığında yığma taş duvarlara sahiptir. Bu sebeple yapı yı̆̆ma duvar sisteminin yanal ötelenme rijitliği oldukça fazladır. Tablo 5'den görüldüğü üzere, yapıda hesaplanmış olan yatay yer değiştirme miktarları duvar yüksekliklerine oranla oldukça düşüktür. Tarihi Yapıların Deprem Risklerinin Yönetimi Kılavuzunda verilmiş olan ve Şekil 8'de gösterilen yanal ötelenme oranları açısından, yapı sismik performans düzeyleri grafiğinde ele alınan yapının yığma duvar sisteminde yanal ötelenme miktarı yaklaşık \% 0,3 sınırını aşmamaktadır.

Tablo 5. Yığma taş duvar sistemi yatay ötelenme miktarları

\begin{tabular}{ccccc}
\hline Doğrultu & Duvar & Yükseklik (mm) & $\begin{array}{c}\text { Yatay Yer } \\
\text { Değiştirme (mm) }\end{array}$ & \% Ötelenme \\
\hline \multirow{3}{*}{$\mathbf{X}$} & $\mathbf{A 1}$ & 5565 & 1.24 & $\mathbf{0 . 0 2 2}$ \\
& $\mathbf{A 2}$ & 5810 & 2.27 & $\mathbf{0 . 0 3 9}$ \\
& $\mathbf{A 3}$ & 5565 & 1.27 & $\mathbf{0 . 0 2 2}$ \\
& $\mathbf{A 4}$ & 5810 & 2.35 & $\mathbf{0 . 0 4 0}$ \\
\hline & B1 & 5185 & 0.92 & $\mathbf{0 . 0 1 7}$ \\
$\mathbf{H}$ & B2 & 5320 & 0.66 & $\mathbf{0 . 0 1 2}$ \\
& B3 & 5320 & 0.64 & $\mathbf{0 . 0 1 2}$ \\
& B4 & 5320 & 0.68 & $\mathbf{0 . 0 1 2}$ \\
\hline
\end{tabular}

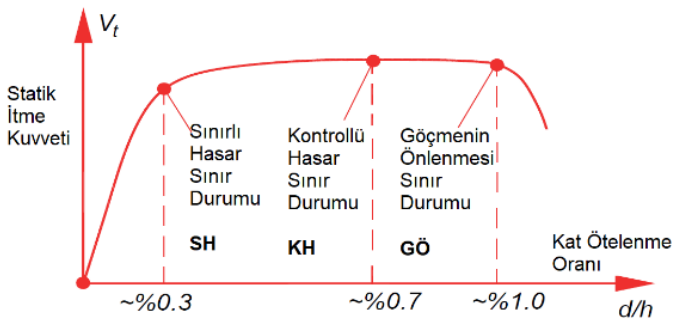

Şekil 8. Yanal ötelenme oranlarına göre performans düzeyleri

\subsection{Taş duvar sistemi kayma güvenliğinin kontrolü}

Yığma tipi yapılarda deprem yükleri duvarlarda kayma gerilmeleri oluşturur. Yı̆̆ma yapıların deprem dayanımı büyük ölçüde duvarların kesme kuvveti taşıma gücüne bağlıdır. Türkiye Bina Deprem Yönetmeliğine göre, duvar karakteristik kayma dayanımı $\mathrm{f}_{\mathrm{vk}}$, aşağıda verilen Denklem 2 ile hesaplanmaktadır. $\mathrm{Bu}$ yaklaşıma göre duvar kayma dayanımı tuğla ile harç arasındaki aderans (yapışma) ve harç-taş ya da taş-taş arasındaki sürtünme parametrelerine bağlı olarak değişiklik göstermektedir.

$\mathrm{f}_{\mathrm{vk}}=\mathrm{f}_{\mathrm{vk} 0}+0,4 \sigma_{\mathrm{d}} \leq 0,10 \mathrm{f}_{\mathrm{b}}$

Denklem 2'de verilen parametrelerden, $\mathrm{f}_{\mathrm{vk}}$, duvar üzerinde ortalama düşey gerilmeler kullanılarak elde edilen duvar karakteristik kesme dayanımını, $\mathrm{f}_{\mathrm{vk} 0}$, eksenel gerilmenin 
bulunmadığı durumda karakteristik kesme dayanımını, $\sigma_{\mathrm{d}}$ yük katsayılarıyla çarpılmış düşey yükler ve deprem yüklerinin ortak etkisi altında hesaplanan düşey basınç gerilmesini ve $f_{b}$, kâgir biriminin standartlaştırılmış (boyut etkisinden arındırılmış $100 \times 100 \mathrm{~mm}$ boyutundaki numuneye eşdeğer) ortalama basınç dayanımını tanımlamaktadır. Duvarlarda eksenel gerilmenin bulunmadığı durumda karakteristik kayma dayanımları $\mathrm{f}_{\mathrm{vk} 0}$, Tablo 6’ya göre belirlenmiştir.

Tablo 6. Yığma duvarların karakteristik başlangıç kayma dayanımları (f $\left.\mathbf{f}_{\mathbf{v k 0}}\right)$

\begin{tabular}{cccc}
\hline Kâgir Birim & \multicolumn{2}{c}{ Genel Amaçlı Harç (*) } & İnce Tabaka Harç \\
\hline \multirow{2}{*}{ Tuğla } & M10-M20 & $0.30 \mathrm{MPa}$ & \\
& M2.5-M9 & $0.20 \mathrm{MPa}$ & $0.30 \mathrm{MPa}$ \\
& M1-M2 & $0.10 \mathrm{MPa}$ & \\
\hline BekN & M10-M20 & $0.20 \mathrm{MPa}$ & $0.30 \mathrm{MPa}$ \\
\hline Gaz bekN & M2.5-M9 & $0.15 \mathrm{MPa}$ & $0.30 \mathrm{MPa}$ \\
\hline Doğal veya Yapay Taş & M1-M2 & $0.10 \mathrm{MPa}$ & Kullanılmaz \\
\hline
\end{tabular}
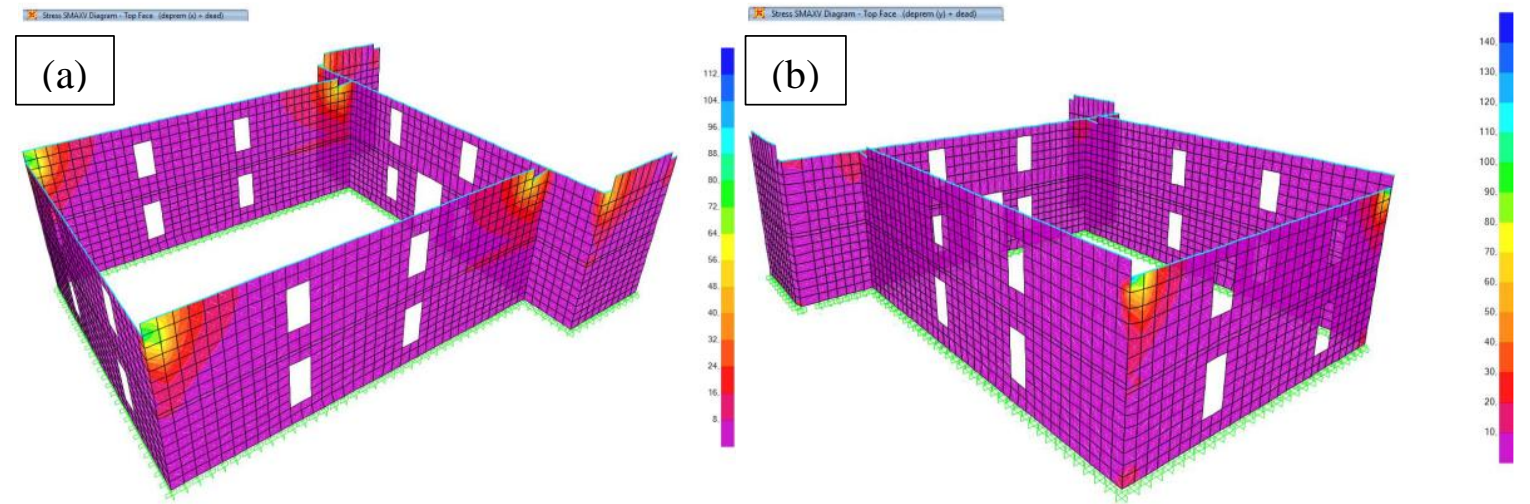

Şekil 9. Yığma taş duvarlarda oluşan kayma gerilmesi dağılımları; (a) X doğrultusu, (b) $\mathrm{Y}$ doğrultusu.

Çalışma kapsamında yığma taş duvarlar için kullanılan karakteristik başlangıç kayma dayanımları 0,10 MPa olarak hesap edilmiştir. Düşey yük altında yapılan analiz sonuçlarına bağlı olarak duvarlarda oluşan basınç gerilmeleri $\left(\sigma_{\mathrm{d}}\right)$ kullanılarak duvarların etkili kayma gerilmeleri ayrıca hesap edilmiştir. Analizler sonucunda taş duvarlarda oluşan en büyük (maksimum) kayma gerilmeleri hesaplanan etkili kayma dayanımları ile karşılaştırılmıştır (Tablo 7).
Yapılan analizler sonucunda her iki yük birleşimde taş duvarlarda oluşan kayma gerilmeleri Şekil 9'da gösterilmektedir. Duvarlarda oluşan en büyük (maksimum) kayma gerilmeleri yapı köşelerinde birleşim noktalarında oluşmaktadır. Ancak, Tablo 6'dan görüldüğü üzere yığma duvarlarda oluşan en büyük (maksimum) kayma gerilmeleri, Denklem 2 yardımıyla hesaplanan etkili kayma dayanımlarını aşmamaktadır. 
Tablo 7. Yığma taş duvarların kayma güvenliği kontrolü

\begin{tabular}{|c|c|c|c|c|}
\hline \multirow[t]{2}{*}{$\begin{array}{c}\text { Deprem } \\
\text { Doğrultusu }\end{array}$} & \multirow[t]{2}{*}{$\begin{array}{l}\text { Yığma Taş } \\
\text { Duvar }\end{array}$} & $\begin{array}{l}\text { Oluşan Basınç } \\
\text { Gerilmesi }\end{array}$ & $\begin{array}{c}\text { Hesaplanan } \\
\text { Etkili Kayma } \\
\text { Dayanımı }\end{array}$ & $\begin{array}{l}\text { Oluşan En Büyük } \\
\text { Kayma Gerilmesi }\end{array}$ \\
\hline & & $\mathrm{kN} / \mathrm{m}^{2}$ & $\mathrm{kN} / \mathrm{m}^{2}$ & $\mathrm{kN} / \mathrm{m}^{2}$ \\
\hline \multirow{8}{*}{$\mathbf{X}$} & $\bar{A} 1$ & 130.52 & 152.208 & 74.14 \\
\hline & A2 & 139.09 & 155.636 & 82.14 \\
\hline & A3 & 183.05 & 173.22 & 95.53 \\
\hline & A4 & 179.05 & 171.62 & 111.73 \\
\hline & B1 & 160.53 & 164.212 & 18.22 \\
\hline & B2 & 164.28 & 165.712 & 51.83 \\
\hline & B3 & 205.43 & 182.172 & 107.71 \\
\hline & B4 & 165.08 & 166.032 & 104.74 \\
\hline \multirow{8}{*}{$\mathbf{Y}$} & A1 & 130.52 & 152.208 & 79.45 \\
\hline & $\mathrm{A} 2$ & 139.09 & 155.636 & 71.2 \\
\hline & A3 & 183.05 & 173.22 & 89.52 \\
\hline & A4 & 179.05 & 171.62 & 71.2 \\
\hline & B1 & 160.53 & 164.212 & 105.56 \\
\hline & B2 & 164.28 & 165.712 & 81.9 \\
\hline & B3 & 205.43 & 182.172 & 94.52 \\
\hline & B4 & 165.08 & 166.032 & 83.12 \\
\hline
\end{tabular}

\subsection{Yığma taş duvar sistemi basınç} dayanımı güvenliğinin kontrolü

Yapıda bulunan yı̆̆ma duvarlar çoğunlukla moloz taştan oluşmaktadır. Moloz taştan oluşan yığma duvarın basınç dayanımı daha önce verilen Tablo 2'den 0,60 Mpa $\left(600 \mathrm{kN} / \mathrm{m}^{2}\right)$ olarak alınmıştır. Yalnızca düşey yükler altında yapılan analiz sonuçlarında, taş duvarlarda oluşan en büyük (maksimum) basınç gerilmeleri hesaplanarak Tablo 7'de gösterilmiştir. Duvarlarda oluşan en büyük (maksimum) basınç gerilmeleri $600 \mathrm{kN} / \mathrm{m}^{2}$ olarak belirlenen basınç dayanımı değerini aşmamıştır. Bununla birlikte düşey yükler altında yapılan analiz sonuçlarında duvar sisteminde basınç ve çekme gerilmelerinin birlikte meydana geldiği Şekil 10'da gösterilmiştir.

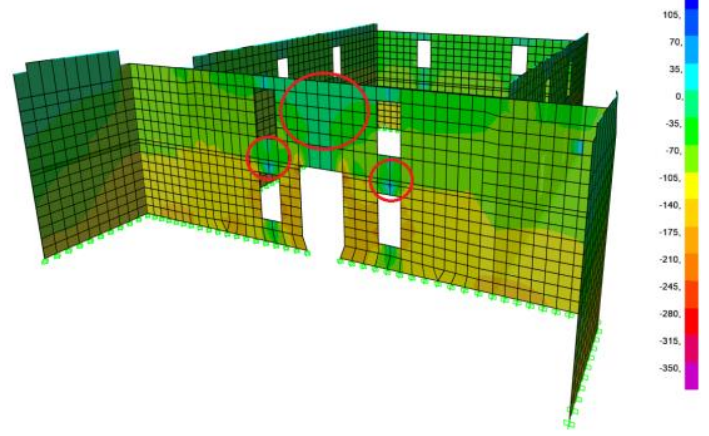

Şekil 10. Duvarlarda oluşan basınç ve çekme gerilmeleri.

\subsection{Yapının deprem performansının belirlenmesi}

Performans kavramı, mevcut yapıların deprem güvenliğinin belirlenmesi için geliştirilmiştir. Kavramın tanımlanmasında iki hususun etkili olduğu görülmektedir. Bunlardan birincisi, deprem etkisi altında taşıyıcı sistemin elastik ve elastik ötesi davranışında, hem taşıyıcı sistem kapasitesinin ve hem de depremin taşıyıcı 
sistemden olan talebine etkisinin olabildiğince gerçekçi biçimde göz önüne alınmasıdır. İkinci husus gelişen taşıyıcı sistem davranış bilgisini ve bilgisayar yazılımlarının sunduğu ayrıntılı çözüm tekniğini kullanarak, binada kabullenilen hasarın daha ayrıntılı olarak sayısal tanımlanması ve bunun deprem güvenliği değerlendirmesine yansitılmasıdır.

Doğrusal analiz sonuçlarıyla yapılan değerlendirmeler neticesinde, yapının sismik performans seviyesi, Tarihi Yapıların Deprem Risklerinin Yönetimi Kılavuzundaki sinır durumlar tablosuna göre belirlenmiştir. Sismik performans düzeylerine karş1lık gelen hesap yöntemleri ve sinır durumları Tablo 8'de özetlenmiştir. Düşey yük ve öngörülen azaltılmamış deprem etkisinde hesaplanan gerilme değerleri ve azaltılmamış deprem etkisinde ötelenme oranı \% 0,3 sinırını aşmadığı için yapının performans düzeyi Sınırlı Hasar (SH) olarak belirlenmiştir.

Tablo 8. Sismik performans düzeylerine karşılık gelen hesap yöntemleri ve sınır durumlar

\begin{tabular}{|c|c|}
\hline $\begin{array}{c}\text { Performans } \\
\text { Düzeyi }\end{array}$ & Hesap Yöntemi ve Sınırlar \\
\hline $\begin{array}{l}\text { Sinırlı Hasar } \\
\text { Sinır Durum } \\
(\mathrm{SH})\end{array}$ & $\begin{array}{l}\text { Doğrusal hesap yöntemi kullanılıyor; } \\
\text { a) Düşey yük ve azaltılmamış öngörülen deprem etkisinde bulunan hesap } \\
\text { dayanımları aşılmıyor. } \\
\text { b) Azaltılmamış deprem etkisinde öteleme oranı } \% 0,3 \text { sınırını aşmıyor. }\end{array}$ \\
\hline $\begin{array}{l}\text { Kontrollü Hasar } \\
\text { Sinır Durumu } \\
(\mathrm{KH})\end{array}$ & $\begin{array}{l}\text { Doğrusal hesap yöntemi kullanılıyor; } \\
\text { a) Düşey yük ve } 3 \mathrm{Ra} \leq \text { ile azaltılmış öngörülen deprem etkisinde bulunan hesap } \\
\text { dayanımları aşılmıyor. } \\
\text { b) Azaltılmamış deprem etkisinde öteleme oranı \% } 0,7 \text { sınırını aşmıyor. } \\
\text { 2. Doğrusal olmayan hesap yöntemi kullanılıyor; } \\
\text { a) Öteleme oranı \% } 0,7 \text { sınırının aşmıyor. } \\
\text { b) Malzemelerin şekil değiştirme kapasiteleri aşılmıyor. }\end{array}$ \\
\hline $\begin{array}{l}\text { Göçme Öncesi } \\
\text { Sınır Durumu } \\
\text { (GÖ) }\end{array}$ & $\begin{array}{l}\text { Doğrusal hesap yöntemi kullanılıyor; } \\
\text { a) Düşey yük ve } 3 \mathrm{Ra} \leq \text { ile azaltılmış öngörülen deprem etkisinde bulunan hesap } \\
\text { dayanımları belirli bir oranla ( } \sim .5 \text { katı) aşılabilir. } \\
\text { b) Azaltılmamış deprem etkisinde öteleme oranı } \% 1 \text { sınırını aşmıyor. } \\
\text { Doğrusal olmayan hesap yöntemi kullanılıyor; } \\
\text { a) Öteleme oranı \% } 1 \text { sınırının aşmıyor. } \\
\text { b) Malzemelerin şekil değiştirme kapasiteleri sınırlı oranda ( } \sim 1.2 \text { katı) aşılabilir. }\end{array}$ \\
\hline
\end{tabular}




\section{Sonuç}

Kültür mirası açısından oldukça zengin olan ülkemizde tarihi yapılar büyük bir çeşitlenme göstermektedir. Anadolu'nun aktif bir deprem kuşağı üzerinde bulunması nedeniyle yurdumuzdaki tarihi yapilar depremlerden etkilenmişlerdir. Depremlere bağlı hasarların azaltılması, anıtların sürekli bakımlarının yapılması ve izlenmesi ile mümkün olmaktadır.

Çalışma kapsamında örnek olarak ele alınan Tarihi Yanıkoğlu Camisinde yapılan ölçümler ve gözlemlere dayalı olarak yapının analitik modeli oluşturulmuştur. Yapı konumuna özel olarak seçilen deprem spektrumları ile eşdeğer deprem yükü hesaplanmıştır. Yapının kendi ağırlığı ve hesaplanan deprem kuvvetleri altında yapılan analizler ile elde edilen sonuçlara bağlı olarak yapının sismik performans düzeyi Vakıflar Genel Müdürlüğünce yayımlanan Tarihi Yapılar İçin Deprem Risklerinin Yönetimi Kılavuzuna göre belirlenmiştir. $\mathrm{Bu}$ çalışma ile tarihi yığma yapıların sismik performanslarının değerlendirilmesinde pratik bir yaklaşım ortaya konulmuştur.

\section{Kaynaklar}

http://tdth.afad.gov.tr, (2018), “Türkiye Deprem Tehlikesi Haritaları", AFAD.

TBDY (2018) (Türkiye Bina Deprem Yönetmeliği), T.C. Resmi Gazete.

TYIDRYK (2017), "Tarihi Yapılar İçin Deprem Risklerinin Yönetimi Kılavuzu", Vakıflar Genel Müdürlüğü.

Efe, H., Çağatay, K., (2011), "Çeşitli Masif Ağaç Malzemelerin Bazı Fiziksel ve Mekanik Özelliklerinin Belirlenmesi”, Politeknik Dergisi, 14(1).

Green, DW., Winandy, JE., Kretschmann, DE, (1999), "Mechanical properties of wood", In: Wood handbook, FPL-GTR113, US. Department of Agriculture, Forest Service, Forest Products Laboratory, Madison.

SAP $2000 \quad$ "Structural Analysis Programme", 19.2, Computers and Structures Inc. Berkeley, CA.

Magenes, G., Penna, A., (2011), "Seismic Design and Assessment of Masonry Buildings in Europe: Recent Research and Code Development Issues", 9th Australasian Masonry Conference, Queenstown, New Zealand, 15(18), 583603.

Bayülke, N., (2011), "Yığma Yapıların Deprem Davranışı ve Güvenliği”, 1. Türkiye Deprem Mühendisliği ve Sismoloji Konferansı.

Çelik, A., \& Birdal, F. (2017). Ahşap Taşıyıcı Sistemli Tarihi Camilerin Güçlendirilmesine Yönelik Bir Durum Çalışması. 